\title{
Burden of Resistant Hypertension in Hypertensive Patients with Non-Dialysis Chronic Kidney Disease
}

\author{
Luca De Nicola $^{a}$ Silvio Borrelli ${ }^{a}$ Francis B. Gabbai ${ }^{c}$ Paolo Chiodini ${ }^{b}$ \\ Pasquale Zamboli $^{a}$ Carmela lodice $^{\mathrm{a}}$ Santo Vitiello ${ }^{a}$ Giuseppe Conte ${ }^{\mathrm{a}}$ \\ Roberto Minutolo ${ }^{a}$ \\ aDivision of Nephrology, and ' ${ }^{\mathrm{D}}$ Department of Biostatistics, Second University of Naples, Naples, Italy; \\ 'Division of Nephrology, VA San Diego Healthcare System and University of California, San Diego, Calif., USA
}

\section{Key Words}

Blood pressure control • Hypertension - Survival analysis •

Chronic kidney disease

\begin{abstract}
Background/Aims: In chronic kidney disease (CKD), no data on resistant hypertension $(\mathrm{RH})$ are so far available despite the high prevalence of uncontrolled hypertension. We evaluated frequency, correlates and prognosis of $\mathrm{RH}$ in 300 consecutive incident hypertensive CKD patients in an academic renal clinic. Methods: RH was defined as office blood pressure $(B P) \geq 130 / 80 \mathrm{~mm} \mathrm{Hg}$ despite $\geq 3$ drugs at full dose including a diuretic, or as BP at goal with $\geq 4$ full-dose drugs. Patients were evaluated at referral and after 6 months of nephrology management; thereafter, they were included in a renal survival analysis lasting 37.6 months. Results: On referral, glomerular filtration rate was $41.3 \pm 16.6 \mathrm{ml} / \mathrm{min} / 1.73 \mathrm{~m}^{2}$ and BP $148 \pm 23 / 81 \pm 12 \mathrm{~mm} \mathrm{Hg}$. After 6 months, BP decreased by $8 \pm 23 / 3 \pm 12 \mathrm{~mm} \mathrm{Hg}$. From referral to month 6 , $\mathrm{RH}$ detection increased from 26 to $38 \%$ due to the significant increment in full-dose antihypertensive medications (from 2.0, IQR 1.0-3.0 to 2.5, IQR 2.0-3.0). Diabetes and proteinuria predicted the incidence of $\mathrm{RH}$ at month 6 . Presence of $\mathrm{RH}$ at month 6 was associated with greater risk of renal death (HR,
\end{abstract}

$1.85,95 \% \mathrm{Cl}, 1.13-3.03)$, independent of main clinical features and degree of BP control. Conclusion: In CKD, RH is prevalent and associated with decreased renal survival, independent of BP levels.

Copyright $\odot 2011$ S. Karger AG, Basel

\section{Introduction}

Resistant hypertension (RH) is defined as office blood pressure (BP) that remains above goal $[>140 / 90 \mathrm{~mm} \mathrm{Hg}$ for the overall population and $\geq 130 / 80 \mathrm{~mm} \mathrm{Hg}$ for those with diabetes mellitus or chronic kidney disease (CKD)] despite the use of at least 3 antihypertensive agents at full dose including a diuretic or the use of 4 or more antihypertensive agents at full dose in the setting of optimal BP control, in the absence of white coat hypertension (WCH) or poor compliance to prescribed therapy that identify the condition of pseudoresistance [1-3]. The concurrent evaluation of BP, number and dose of antihypertensive

Part of this study was presented and published in abstract form [Am Soc Nephrol 2008;19:307A] at the 2008 Renal Week of the American Society of Nephrology.

\section{KARGER}

Fax +41613061234 E-Mail karger@karger.ch www.karger.com
Prof. Luca De Nicola

Cattedra di Nefrologia, Dip. Gerontologia, Geriatria, Mal. Metabolismo

Seconda Università di Napoli, Piazza Miraglia

IT-80131 Napoli (Italia)

Tel./Fax +39 081254 9409, E-Mail luca.denicola@unina2.it 
drugs at the individual patient level and adherence to prescription is therefore necessary to distinguish between $\mathrm{RH}$ and uncontrolled hypertension.

A scientific statement from the American Heart Association (AHA) has recently highlighted the need to improve awareness and knowledge of $\mathrm{RH}$ which remains limited despite the presumed high cardiovascular $(\mathrm{CV})$ risk associated with this condition [2]. In this context, evaluation of CKD patients is highly relevant for two reasons. First, the prevalence of renal disease is rapidly rising worldwide with approximately $10 \%$ of the adult population currently affected [4]. Notably, 65-95\% of CKD patients develop hypertension as the glomerular filtration rate (GFR) declines from 85 to $15 \mathrm{ml} / \mathrm{min}$ [5] and hypertension constitutes a major risk factor for the progression of renal disease [5-10], as well as to the high CV risk observed from the early stages of CKD [5, 10-13]. Second, the burden and importance of RH in CKD is currently unknown. Indeed, several surveys in CKD patients demonstrate a high incidence of uncontrolled hypertension in clinical practice [14-21]; however, the value of these surveys is limited due to the absence of information on the number/dose of antihypertensive agents utilized and the cross-sectional design of these audits which precludes any evaluation of the effects of intensification of antihypertensive therapy on BP control. Landmark hypertension trials in CKD also attest to the difficulty of achieving BP goal in as many as $50 \%$ of non-diabetic and $70 \%$ of diabetic patients despite titration of antihypertensive therapy to goal and the use of 3.5-4.5 antihypertensive agents per patient [7,22-24]. However, also these trials do not specifically address the role of $\mathrm{RH}$.

We therefore conducted a retrospective study to evaluate $\mathrm{RH}$ in an outpatient CKD clinic to assess its magnitude after 6 months of nephrology management, its predictors and its association with renal survival.

\section{Methods}

\section{Patients}

We considered eligible for the analysis all consecutive incident patients, referred because of CKD diagnosis by the general practitioners working in the same area of our hospital, who presented to the outpatient clinic of the Department of Nephrology, Second University of Naples, Naples, Italy, from January 1, 2002 to December 31, 2006

Patients were included if not on dialysis and without a kidney transplant, with CKD stages $2-5$, that is, either with an estimated GFR (eGFR) $<60 \mathrm{ml} / \mathrm{min} / 1.73 \mathrm{~m}^{2}$ or eGFR $60-90 \mathrm{ml} / \mathrm{min} / 1.73 \mathrm{~m}^{2}$ plus proteinuria $>0.3 \mathrm{~g} / 24 \mathrm{~h}$ in two consecutive visits with an interval $\geq 3$ months.
Exclusion criteria were: less than two visits during the first 6 months of follow-up in the renal clinic, BP on the first visit $<130 / 80 \mathrm{~mm} \mathrm{Hg}$ without antihypertensive therapy, evidence of acute kidney injury, active malignancy, severe liver or heart failure, active steroid or immunosuppressive therapy use. Patients were also excluded from analyses when adherence to prescribed therapy was poor; compliance was evaluated at each visit in the clinic by checking returned medications and using specific questions on assumption of pharmacological therapy directed not only to the patient but, more importantly, to family members. Specifically, we ask the number of times the patient has not taken the prescribed medications in the last week as well as if he/she takes medications at the indicated time. The patient is identified as poorly compliant to therapy, and therefore excluded from studies, if the missing rate is $\geq 20 \%$ or the indicated time is not respected in two visits. In our experience, this approach has been more efficacious than the individual pill count in identifying non-adherent patients. On the other hand, to minimize the problem poor adherence, participating nephrologists dedicated time during each visit to highlight to the patient and family members of the high cardiorenal risk associated with CKD and the major benefits of compliance with therapy. Presence of WCH was an additional exclusion criterion; specifically, patients not at goal on the first visit were asked to report home $\mathrm{BP}$ values obtained by electronic devices preliminarily tested in the office or underwent $24 \mathrm{~h} \mathrm{am-}$ bulatory BP monitoring (ABPM) to exclude this condition characterized by $\mathrm{BP} \geq 130 / 80 \mathrm{~mm} \mathrm{Hg}$ in the office with either daytime $<135 / 80 \mathrm{~mm} \mathrm{Hg}$ on ABPM or BP $<135 / 80 \mathrm{~mm} \mathrm{Hg}$ at home.

\section{Study Design}

This is a retrospective study using a database that included all consecutive patients incident in our outpatient clinic. The database provided comprehensive and detailed information on demographic, clinical, laboratory, therapeutic features and presence or absence of left ventricular hypertrophy at echocardiography ( $\mathrm{LVH}$ ) and history of CV disease, defined as hospitalization for coronary heart disease, cerebrovascular and peripheral vascular disease, or heart failure. Baseline treatment was that prescribed by the general practitioner; from then on, treatment was that prescribed by the nephrologist in the clinic.

To discriminate between patients with and without RH, we reviewed the BP level and drug regimen for each individual during the first visit in our clinic (referral or baseline), and at the month 6 and month 12 visit in the clinic, for a total number of 900 visits. At each visit, a patient was defined as having $\mathrm{RH}$ if office $\mathrm{BP}$ was either $\geq 130$ and/or $\geq 80 \mathrm{~mm} \mathrm{Hg}$ in spite of the use of $\geq 3$ antihypertensive agents at full dose including a diuretic or $<130 / 80 \mathrm{~mm} \mathrm{Hg}$ with $\geq 4$ agents at full dose [2]. The daily doses of antihypertensive agents that were considered as 'full dose' according to the manufacturer's recommendations in Italy are reported in the Appendix.

After completion of the first 6 months in the clinic, data on renal death were collected until November 30, 2009.

The study was approved by the Institutional Review Board and all patients gave informed consent to use their data.

Management of CKD in the Renal Clinic

Patients were always seen by the same nephrologists in the clinic. The frequency of visits was determined by the clinical status of the patient and K/DOQI guidelines $[25,26]$. The five par- 
ticipating nephrologists are all well versed and committed to the therapeutic goals recommended by K/DOQI. Specifically, the treatment of $\mathrm{BP}$ was aimed at reaching both a systolic $\mathrm{BP}<130$ and a diastolic $\mathrm{BP}<80 \mathrm{~mm} \mathrm{Hg}$. All patients were instructed to restrict dietary salt ( $<6 \mathrm{~g} \mathrm{NaCl} /$ day) and protein $(\leq 0.8 \mathrm{~g} / \mathrm{kg}$ b.w./day) by providing personalized written regimens. Antihypertensive medications were distributed from 08:00 to 22:00 h; doses of furosemide $\geq 50 \mathrm{mg} /$ day were also divided in two administrations (08:00 and 20:00 h). All prescribed antihypertensive medications were commercially available and totally reimbursed.

Analyses of blood and urinary samples were performed in the central laboratory of the hospital. GFR was estimated by the 4 -variable Modification of Diet in Renal Disease (MDRD) Study equation. 24-Hour urine collection was obtained at each visit and used for measurement of proteinuria, urinary excretion of $\mathrm{Na}$ $(\mathrm{UNaV})$ and urea. The latter two measurements were aimed at assessing the adherence to the prescribed diet. The collection was considered inadequate and repeated if the creatinine excretion was outside of the $60-140 \%$ range of the value calculated according to Dwyer and Kenler [27].

BP measurement was performed at each visit by the nephrologist in a quiet environment, in the morning, using a mercury sphygmomanometer with a cuff size of appropriate dimension and with the patient in the sitting position after $10 \mathrm{~min}$ of rest. The first and fifth Korotkoff sounds were used to define systolic and diastolic BP values; the mean of three consecutive readings taken $2 \mathrm{~min}$ apart were considered for this analysis.

The patients who did not achieve the BP goal were screened for secondary causes of hypertension other than CKD by history, physical examination and laboratory studies. Ancillary studies were obtained as needed based on the findings of the routine examinations, except for renal ultrasound which was obtained in all patients.

\section{Statistics}

Continuous variables are reported as either mean \pm SD or median and interquartile range (IQR) on the basis of their distribution. Comparisons of continuous variables with normal distribution were performed using paired or unpaired Student's t test. For variables with non-normal distribution we used paired or unpaired Wilcoxon non-parametric test. Categorical variables are expressed as percent and analyzed by $\chi^{2}$ test or by McNemar test.

Multivariable logistic regression analysis was used to identify baseline factors associated with a risk of having RH at month 6 visit. The model was built by identifying a priori the main potential determinants of $\mathrm{RH}$; the model accounted for demographic (age, gender), clinical characteristics (diabetes, body mass index, $\mathrm{LVH}$, previous CV events, 24-hour urinary sodium) and severity of CKD (eGFR, proteinuria). Baseline BP was not added in the final analysis because of its high correlation with the month 6 value which was being used to establish the presence or absence of RH.

For the survival analysis, the primary composite end-point was the time to renal death defined as the time from the month 6 visit to all-cause death or dialysis/renal transplantation, whichever occurred first. We analyzed the unadjusted association of $\mathrm{RH}$ diagnosis at month 6 with the time to renal death by using Kaplan-Meier survival curves compared by log-rank test. The multivariable Cox proportional-hazards model was used to estimate the hazard ratio (HR) and the corresponding 95\% confi- dence intervals (CI), adjusted for the effect of potentially confounding variables identified a priori (age, gender, diabetes, BP goal achievement, CV disease, eGFR, proteinuria). A two-tailed $\mathrm{p}$ value $<0.05$ was considered significant. Data were analyzed using SPSS 12.0 (SPSS Inc., Chicago, Ill., USA).

\section{Results}

\section{Whole Cohort Analysis}

550 patients were eligible for this study, of which 250 were excluded for various reasons (fig. 1), leaving 300 patients to be included in this analysis. In particular, 148 patients were excluded because of pseudoresistance, 28 were in fact found poorly adherent to therapy and 120 were identified as having WCH (91 by home BP and 29 by ABPM). Since diagnosis of WCH based on home BP measurements was reported in the charts as category (yes/no), no data on these measurements are available. Conversely, in the $29 \mathrm{WCH}$ patients diagnosed by ABPM, mean daytime $\mathrm{BP}$ was $122 \pm 7 / 68 \pm 6 \mathrm{~mm} \mathrm{Hg}$ and nighttime was $116 \pm 16 / 62 \pm 8 \mathrm{~mm} \mathrm{Hg}$. When considering out-of-office BP values in WCH patients, $\mathrm{RH}$ was detected in the same percentage of patients when office measurements (20.8\%) were compared to ABPM/home BP (20\%). By definition, $\mathrm{RH}$ patients of the latter subgroup were characterized by daytime/home BP at target despite treatment with $\geq 4$ full-dose drugs including a diuretic. All patients were Caucasians. Enrolled patients had a high CV risk profile including advanced age, high body mass index and large prevalence of diabetes, $\mathrm{LVH}$ and $\mathrm{CV}$ disease (table 1). On referral, proteinuria was $\geq 1.0 \mathrm{~g} / 24 \mathrm{~h}$ in $23 \%$ of the cohort (46\% of stage 2 patients).

Most patients had systo-diastolic hypertension at baseline (table 2). In the first 6 months of management in clinic, BP decreased on average $8 \pm 23 / 3 \pm 12 \mathrm{~mm} \mathrm{Hg}$ and the prevalence of BP goal increased by $57 \%$, from 12.3 to $19.3 \%$. The improvement in BP control was due predominantly to the intensification of antihypertensive therapy since 24-hour sodium excretion did not change between the two visits. At the month 6 visit, $54.7 \%$ of the cohort was taking 3 or more classes of drugs while this occurred in only $16.7 \%$ on referral. Indeed, the median number of antihypertensive drugs increased from 2.0 $(1.5-3.0)$ to $3.0(2.0-3.0)$ from baseline to month 6 . The use and dose of furosemide increased by $30 \%$ while prescription of thiazides did not change.

The increment in full-dose antihypertensive medications and diuretic therapy increased the diagnosis of $\mathrm{RH}$ from $26 \%$ on referral to $38 \%$ at month 6 (fig. 1). Specifi- 
Fig. 1. Flow chart of the study. $\mathrm{HF}=$ Severe heart failure; $\mathrm{LC}=$ severe liver cirrhosis; $\mathrm{HD}=$ hemodialysis. Pseudoresistance: white coat hypertension, $\mathrm{n}=120$; poor adherence to therapy, $\mathrm{n}=28$.

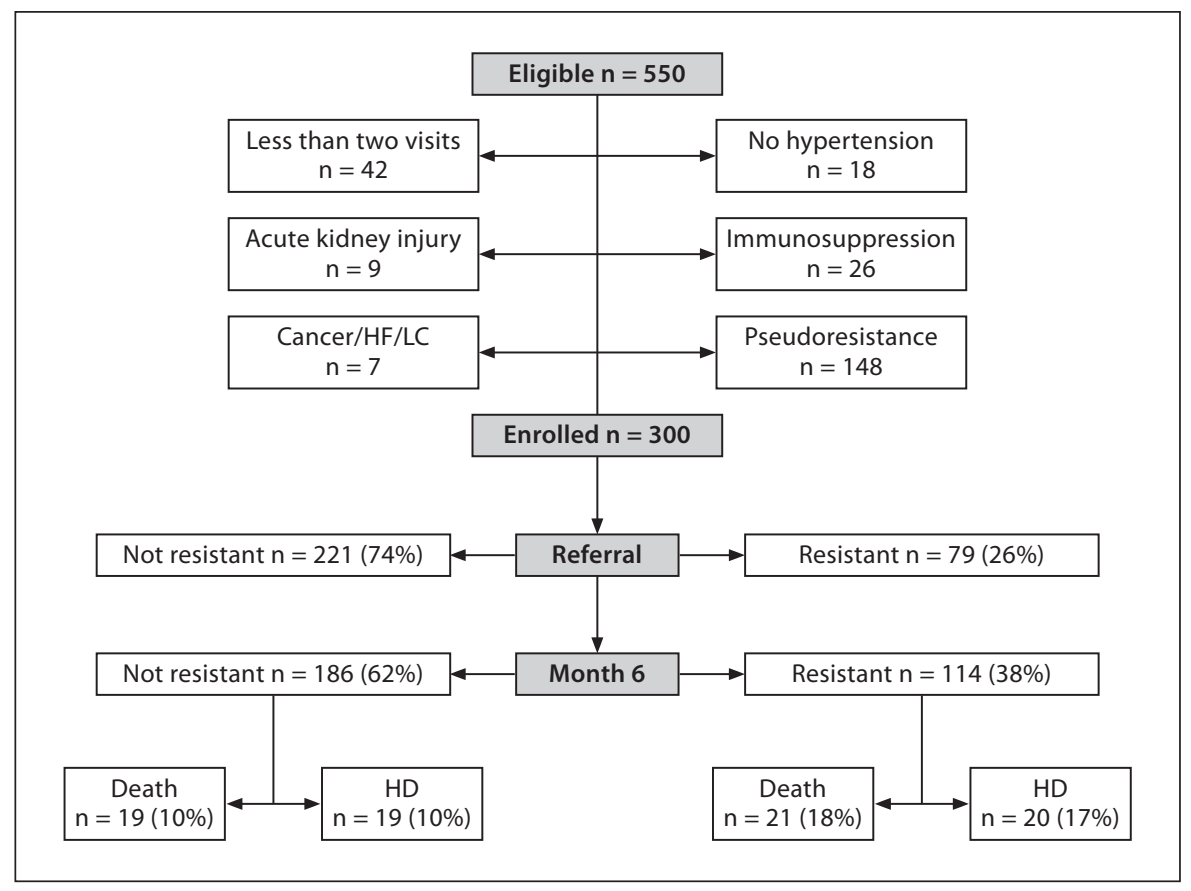

cally, $227(76 \%)$ patients maintained the same status in the two visits, either RH $(\mathrm{n}=62)$ or Not-RH $(\mathrm{n}=165)$, while 73 (24\%) patients changed status from referral to month 6 visit (52 from Not-RH to RH and 21 from RH to Not-RH). Of note, no further increase in $\mathrm{RH}$ detection was observed at month 12 visit $(42 \%, \mathrm{p}=0.401$ vs. month 6$)$.

\section{Comparison of RH versus Not-RH Patients at Month 6}

A larger prevalence of diabetes, diabetic nephropathy, $\mathrm{LVH}$, lower GFR and higher levels of proteinuria and BP characterized $\mathrm{RH}$ patients (table 3 ). $\mathrm{UNaV}$ was the same in $\mathrm{RH}$ and Not-RH patients with adherence to prescribed low salt diet ( $\mathrm{UNaV} \leq 100 \mathrm{mmol} / 24 \mathrm{~h}$ ) observed in only a minority of either group ( $25 \%$ in Not-RH and $28 \%$ in $\mathrm{RH})$. Multivariable logistic regression analysis identified diabetes and proteinuria as baseline factors independently associated with RH status at month 6 (table 4).

The number of visits during the first 6 months of follow-up was greater in $\mathrm{RH}(4.0 \pm 1.9)$ versus Not-RH (3.4 $\pm 1.6 ; \mathrm{p}=0.006$ ). In both groups, BP levels decreased to a similar extent from baseline to the end of the observation; specifically, the reduction of systolic BP was $9 \pm 28$ and $7 \pm 20 \mathrm{~mm} \mathrm{Hg}$ in RH and Not-RH, respectively, whereas diastolic BP decreased by $2 \pm 12$ and $4 \pm 12$ $\mathrm{mm} \mathrm{Hg}$. We did not find any patient with renovascular hypertension, primary hyperaldosteronism, alcohol or drug abuse.

Resistant Hypertension in CKD Patients
Table 1. Demographic and main features in the whole cohort of patients on referral $(n=300)$

$\begin{array}{ll}\text { Age, years } & 67.3 \pm 11.3 \\ \text { Males, \% } & 59.3 \\ \text { Smokers, \% } & 21.7 \\ \text { Body mass index } & 29.7 \pm 5.6 \\ \text { Diabetes, \% } & 38.0 \\ \text { Left ventricular hypertrophy, \% } & 64.7 \\ \text { History of cardiovascular disease, \% } & 37.7 \\ \text { Serum creatinine, mg/dl } & 1.90 \pm 1.01 \\ \text { Causes of renal disease, \% } & \\ \quad \text { Hypertension } & 51.0 \\ \quad \text { Diabetes } & 22.7 \\ \quad \text { GN/IN/PKD } & 10.7 \\ \quad \text { Other } & 15.7 \\ \text { Hemoglobin, g/dl } & 12.8 \pm 2.1 \\ \text { Cholesterol, mg/dl } & 195 \pm 44\end{array}$

Data are expressed as mean \pm SD or median (IQR) or \%.

$\mathrm{GN}=$ Glomerulonephritis; IN = interstitial nephritis; $\mathrm{PKD}=$ polycystic kidney disease.

\section{Renal Survival Analysis}

No renal death (dialysis/transplant or death) was observed in the first 6 months. After the month 6 visit, patients were included in a survival analysis that lasted a median of 37.6 months (IQR 24.3-52.0). During this 
Table 2. Clinical, laboratory and therapeutic features of the whole cohort of patients on referral and after 6 months of follow-up in the renal clinic $(n=300)$

\begin{tabular}{lccc}
\hline & Referral & Month 6 & $\mathrm{p}$ \\
\hline Body weight, kg & $76.4 \pm 15.7$ & $76.2 \pm 15.4$ & 0.195 \\
eGFR, ml/min/1.73 m ${ }^{2}$ & $41.3 \pm 16.6$ & $40.9 \pm 16.6$ & 0.546 \\
SBP, mm Hg & $148 \pm 23$ & $141 \pm 17$ & $<0.0001$ \\
DBP, mm Hg & $81 \pm 12$ & $78 \pm 11$ & $<0.0001$ \\
BP goal achievement, \% & & & 0.015 \\
SBP $<130$ and DBP $<80$ & 12.3 & 19.3 & \\
SBP $\geq 130$ and DBP $<80$ & 23.3 & 27.0 & 0.7 \\
SBP $<130$ and DBP $\geq 80$ & 4.7 & 47.0 & 0.011 \\
SBP $\geq 130$ and DBP $\geq 80$ & 59.7 & $0.18(0.06-0.70)$ & 0.865 \\
Proteinuria, g/24 h & $0.20(0.06-0.87)$ & $155 \pm 66$ & $<0.0001$ \\
Urinary Na, mmol/24 h & $156 \pm 67$ & $2.5(2.0-3.0)$ & 0.0004 \\
Full-dose BP drugs, $\mathrm{n}$ & $2.0(1.0-3.0)$ & 87.0 & 0.019 \\
CEI or ARB, \% & 78.3 & 12.0 & 0.002 \\
CEI + ARB, \% & 7.7 & 50.7 & 0.001 \\
CCB, \% & 43.0 & 37.0 & $<0.0001$ \\
$\beta$-Blockers, \% & 31.0 & 15.0 & 0.207 \\
$\alpha$-Blockers, \% & 7.3 & 29.7 & 0.002 \\
Thiazides, \% & 33.7 & 36.3 & $<0.0001$ \\
Furosemide, \% & 28.0 & $56 \pm 33$ & \\
Furosemide, mg/day & $42 \pm 33$ & & \\
\hline
\end{tabular}

Data are expressed as mean \pm SD or median (IQR) or $\%$.

$\mathrm{SBP}=$ Systolic blood pressure; $\mathrm{DBP}=$ diastolic blood pressure; $\mathrm{eGFR}=\mathrm{GFR}$ value by the 4-variable MDRD equation; $\mathrm{CEI}=$ converting enzyme inhibitor; $\mathrm{ARB}=$ angiotensin II receptor antagonist.

period, renal death occurred in 79 patients (fig. 1). Diagnosis of $\mathrm{RH}$ at month 6 was associated with shorter renal survival (fig. 2). This result persisted after adjustment for the effect of main determinants of renal survival and BP goal (table 5); specifically, the multivariable-adjusted risk for renal death was almost double in RH versus Not-RH patients (HR 1.85, 95\% CI 1.13-3.03). The predictive role of $\mathrm{RH}$ did not change when in the model BP goal was substituted with either systolic (HR for RH: 1.84, 95\% CI 1.14-2.99) or diastolic BP level (HR for $\mathrm{RH}: 1.98,95 \% \mathrm{CI} 1.21-3.22)$. That the predictive role of RH was independent from BP goal or level was also confirmed by the absence of any significant interaction of RH with BP goal $(\mathrm{p}=0.816)$, and either systolic $(\mathrm{p}=$ $0.664)$ or diastolic $(\mathrm{p}=0.686)$ BP level. Similarly, when the hemoglobin value at month 6 visit was added to the model, HR for this parameter was not significant $(0.88$, $0.77-1.02)$ and HR for RH did not change $(1.86,1.14-$ 3.05).

\section{Discussion}

In 2008, the AHA has reinforced the concept that RH is a pathologic condition distinct from uncontrolled hypertension [2]. The concept of RH is clinically relevant even if the definition is somewhat arbitrary with regard to the number of antihypertensive medications required. The purpose of early detection and careful evaluation of patients with $\mathrm{RH}$ is in fact aimed at identifying individuals who have secondary causes of hypertension who may benefit from specific therapeutic considerations $[1,2]$. This point is critical since prognosis of this condition is supposed to be poor. The latter concept holds particularly true in CKD, which constitutes a major cause of hypertension and it is characterized by a well-defined cardiorenal risk from stages as early as CKD 1 or $2[4,13]$.

This study is the first to provide information regarding the burden of RH in CKD patients. The CKD cohort examined was characterized by a high prevalence of advanced age, overweight, diabetes, $\mathrm{LVH}$ and significant history of $\mathrm{CV}$ events. These features are comparable to 
Table 3. Demographic and main clinical and laboratory parameters in patients stratified by diagnosis of $\mathrm{RH}$ at month 6

\begin{tabular}{|c|c|c|c|}
\hline & $\begin{array}{l}\text { Not-RH } \\
(\mathrm{n}=186)\end{array}$ & $\begin{array}{l}\mathrm{RH} \\
(\mathrm{n}=114)\end{array}$ & $\mathrm{p}$ \\
\hline Age, years & $67.6 \pm 11.7$ & $68.0 \pm 10.7$ & 0.815 \\
\hline Male gender, $\%$ & 62.4 & 54.4 & 0.172 \\
\hline Body mass index & $29.3 \pm 5.1$ & $30.1 \pm 6.7$ & 0.187 \\
\hline Smokers, \% & 19.9 & 24.6 & 0.341 \\
\hline Diabetes, \% & 30.6 & 50.0 & 0.001 \\
\hline History of cardiovascular disease, $\%$ & 35.5 & 41.2 & 0.319 \\
\hline Left ventricular hypertrophy, \% & 60.2 & 71.9 & 0.039 \\
\hline Causes of renal disease, $\%$ & & & $<0.0001$ \\
\hline Hypertension & 55.9 & 43.0 & \\
\hline Diabetes & 13.4 & 37.7 & \\
\hline GN/IN/PKD & 12.9 & 7.0 & \\
\hline Other & 17.7 & 12.3 & \\
\hline $\mathrm{eGFR}, \mathrm{ml} / \mathrm{min} / 1.73 \mathrm{~m}^{2}$ & $43.1 \pm 16.7$ & $37.4 \pm 15.8$ & 0.004 \\
\hline Hemoglobin, g/dl & $13.1 \pm 1.7$ & $12.7 \pm 1.8$ & 0.073 \\
\hline Cholesterol, mg/dl & $190 \pm 39$ & $192 \pm 43$ & 0.797 \\
\hline Proteinuria, g/24 h & $0.14(0.05-0.54)$ & $0.26(0.10-1.25)$ & 0.001 \\
\hline Urinary $\mathrm{Na}, \mathrm{mmol} / 24 \mathrm{~h}$ & $152 \pm 68$ & $151 \pm 69$ & 0.872 \\
\hline Systolic BP, mm Hg & $137 \pm 16$ & $146 \pm 17$ & $<0.0001$ \\
\hline Diastolic BP, mm Hg & $77 \pm 11$ & $80 \pm 11$ & 0.011 \\
\hline $\mathrm{BP}<130 / 80 \mathrm{~mm} \mathrm{Hg}, \%$ & 25.8 & 7.9 & $<0.0001$ \\
\hline BP drugs, $\mathrm{n}$ & $2.0(1.0-3.0)$ & $4.0(3.0-4.0)$ & $<0.0001$ \\
\hline Full-dose BP drugs, $\mathrm{n}$ & $2.0(1.5-2.5)$ & $3.5(3.0-4.0)$ & $<0.0001$ \\
\hline CEI or $\mathrm{ARB}, \%$ & 84.4 & 91.2 & 0.088 \\
\hline
\end{tabular}

Data are expressed as mean $\pm \mathrm{SD}$ or median (IQR) or \%.

$\mathrm{GN}=$ Glomerulonephritis; $\mathrm{IN}=$ interstitial nephritis; $\mathrm{PKD}=$ polycystic kidney disease; $\mathrm{eGFR}=\mathrm{GFR}$ value by the 4-variable MDRD equation; $\mathrm{BP}=$ blood pressure; $\mathrm{CEI}=$ converting enzyme inhibitor; $\mathrm{ARB}=$ angiotensin II receptor antagonist.

Table 4. Multivariable logistic regression analysis of baseline predictors of $\mathrm{RH}$ at month 6

\begin{tabular}{lccc}
\hline Parameter & OR & $95 \% \mathrm{CI}$ & $\mathrm{p}$ \\
\hline Age, years & 1.00 & $0.98-1.03$ & 0.770 \\
Male gender & 0.57 & $0.32-1.01$ & 0.054 \\
Body mass index & 1.01 & $0.96-1.05$ & 0.881 \\
Diabetes & 1.97 & $1.18-3.28$ & 0.009 \\
History of CVD & 1.21 & $0.71-2.07$ & 0.477 \\
Left ventricular hypertrophy & 1.41 & $0.81-2.44$ & 0.224 \\
eGFR, ml/min/1.73 m ${ }^{2}$ & 0.98 & $0.97-1.01$ & 0.062 \\
Proteinuria, g/24 h & 1.29 & $1.07-1.56$ & 0.009 \\
Urinary sodium, mmol/24h & 1.00 & $0.99-1.01$ & 0.369 \\
\end{tabular}

CVD = Cardiovascular disease; $\mathrm{eGFR}=\mathrm{GFR}$ value by the 4-variable MDRD equation.
Table 5. Multivariable Cox analysis of determinants of renal death occurring during the follow-up subsequent to month 6 visit

\begin{tabular}{lccc}
\hline Parameter & HR & $95 \% \mathrm{CI}$ & $\mathrm{p}$ \\
\hline Resistant hypertension & 1.85 & $1.13-3.03$ & 0.014 \\
Age, years & 0.99 & $0.97-1.01$ & 0.144 \\
Male gender & 1.40 & $0.85-2.32$ & 0.187 \\
$\mathrm{BP}<130 / 80 \mathrm{~mm} \mathrm{Hg}$ & 0.75 & $0.37-1.53$ & 0.434 \\
Diabetes & 0.69 & $0.42-1.12$ & 0.133 \\
History of CVD & 1.37 & $0.82-2.29$ & 0.231 \\
eGFR, $\mathrm{ml} / \mathrm{min} / 1.73 \mathrm{~m}^{2}$ & 0.92 & $0.90-0.93$ & $<0.0001$ \\
Proteinuria, g/24 h & 1.16 & $1.07-1.25$ & $<0.001$ \\
\hline
\end{tabular}

CVD = Cardiovascular disease; $\mathrm{eGFR}=\mathrm{GFR}$ value by the 4-variable MDRD equation. 


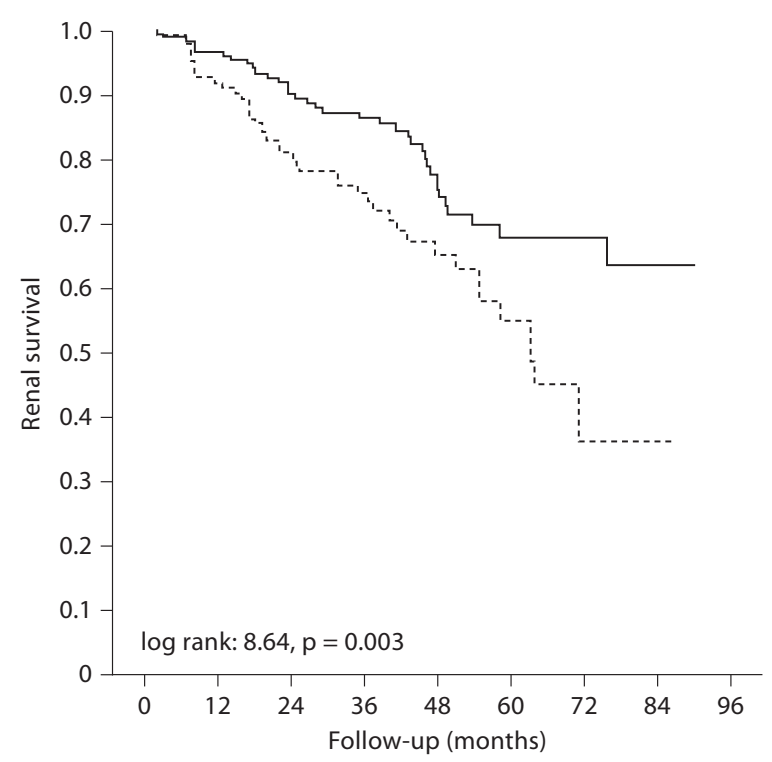

Fig. 2. Time to renal death after diagnosis of $\mathrm{RH}$ at month 6 visit $(--$ - $\mathrm{RH} ;-=$ Not-RH).

those previously reported in a recent national survey of CKD patients followed in 26 Italian renal clinics [14]. In the presence of such an unmodifiable burden of CV risk, uncontrolled hypertension was a common finding; almost $90 \%$ patients, in fact, had basal BP levels $\geq 130 / 80$ $\mathrm{mm} \mathrm{Hg}$ on referral.

Management in the renal clinic was associated with a significant improvement in BP control over the initial 6 months with a relative increase of $57 \%$ in the prevalence of BP goal. The effectiveness of this therapeutic approach is further supported by a final control rate of about $20 \%$, which is higher than the one observed in the recent Italian multicenter survey where only $12 \%$ of the prevalent CKD patients had BP $<130 / 80$ [14]. The increased use of full-dose antihypertensive medications and diuretics was critical to improve identification of resistant patients; prevalence of $\mathrm{RH}$ increased in fact by $46 \%$ from referral to month 6 (fig. 1).

These results add important information regarding the magnitude of RH in CKD. Indeed, no study has specifically addressed the prevalence of $\mathrm{RH}$ in $\mathrm{CKD}$ as in the general population. A high prevalence has only been hypothesized from analyses of cross-sectional and hypertension outcome studies showing that $20-50 \%$ of patients have uncontrolled hypertension despite multiple drug therapy $[2,3]$.

Several risk factors have been proposed for $\mathrm{RH}$ in the general population including advanced age, diabetes, obesity, renal disease and LVH [1-3]. Our study suggests that RH has peculiar characteristics in CKD since diabetes and proteinuria emerged as the only significant risk factors for RH in our cohort (table 4). This finding adds further insights into the concept that diabetes and proteinuria are associated with poor BP control [14-18, 28, 29]. It is reasonable to hypothesize that a more advanced vascular damage may play a determining role in the development of $\mathrm{RH}$ in CKD. In this regard, endothelium dysfunction and arterial stiffness, which are typical features of diabetes, have been also identified in proteinuric patients [30, 31]. In particular, recent studies in CKD have shown that proteinuria, rather than GFR, relates to the severity of hypertension [29]. Furthermore, although low GFR is recognized as a CV risk factor [13], proteinuria in CKD patients is considered a better marker of the presence of vascular disease [32,33].

We found no relationship between salt intake and $\mathrm{RH}$ in our CKD cohort (table 4). This finding only apparently contrasts with recent studies indicating the presence of volume expansion and sodium sensitivity of BP in non-CKD patients with $\mathrm{RH}[34,35]$. Indeed, these features, while being present only in a limited number of patients with essential hypertension, are common in $\mathrm{CKD}$, especially when adherence to the prescribed dietary salt restriction is low $[5,14-17,36]$, as was the case in our cohort where the vast majority of patients had high values of 24-hour $\mathrm{UNaV}$. A determining role of salt intake is therefore hard to verify in our cohort and we cannot exclude that intensive dietary salt restriction could be effective in reducing $\mathrm{BP}$ in $\mathrm{CKD}$ patients with $\mathrm{RH}$, as demonstrated in non-CKD patients [35].

Indirect evidence from population studies and clinical trials in non-CKD patients suggests that $\mathrm{RH}$, being a proxy for severe vascular damage and target-organ damage, heralds unfavorable prognosis [1-3]. The current study supports this hypothesis in CKD by showing, for the first time, an association between $\mathrm{RH}$ and renal survival (fig. 2). In particular, risk for renal death was $85 \%$ greater in patients who were identified as resistant at month 6 independent of main clinical features. Noteworthy, the predictive role of $\mathrm{RH}$ was also independent of the degree of BP control; this finding demonstrates that in CKD patients diagnosis of $\mathrm{RH}$ has a clinical meaning distinct from achieved BP levels. 
Our study provides novel information regarding the magnitude of RH in CKD patients; however, the estimation is limited by the retrospective design of our study. The study is also limited by the lack of assessment of systemic RAS activity and its contribution to the development of RH [34]. While this limitation precludes us from drawing definitive conclusions on risk profile and mechanism(s) of RH in our CKD patients, the antihypertensive polytherapy and the large use of RAS inhibitors prevent any meaningful evaluation of this system in our patients $[37,38]$. A further limitation is the absence of ambulatory BP control in all RH patients; indeed, although diagnosis of $\mathrm{RH}$ is based on office $\mathrm{BP}$, recent studies have shown a superior predictive role of $A B P M$ versus office BP measures in RH patients [39, 40]. In this regard, we found that within the group of $\mathrm{WCH}$ patients, excluded a priori for being identified as pseudoresistant, $20 \%$ of the patients were characterized by normal out-ofoffice BP in the presence of at least 4 antihypertensive drugs. Such patients should probably be classified as having $\mathrm{RH}$ even though current definition does not include $\mathrm{ABPM} /$ home measures for RH diagnosis. Further studies are needed to gain more insights into this interesting issue.

In conclusion, in hypertensive CKD patients, intensification of antihypertensive therapy allows to properly reveal the frequency of RH; specifically, after 6 months of follow-up in a renal clinic, $\mathrm{RH}$ was identified in $38 \%$ of cases with increased risk in the presence of proteinuria and diabetes. Identification of RH is clinically meaningful as this condition is associated with poor renal survival independent of BP control. Our results should help the design of randomized trials aimed at assessing in CKD patients with $\mathrm{RH}$ the effectiveness of salt restriction and other alternative therapeutic interventions that have been proven to be efficacious in reducing the burden of $\mathrm{RH}$ in non-CKD patients [35, 41-43].

\section{Acknowledgement}

This work was partially supported by a grant from the Italian Government Health Ministry (Ricerca Sanitaria 2006: attività di ricerca finalizzata-articolo 12), Rome, Italy, to L.D.N. in 2006.

\section{Appendix}

Daily doses of antihypertensive agents considered as 'full dose' according to the manufacturer's recommendations in Italy

\begin{tabular}{|c|c|}
\hline Drug & Dose \\
\hline \multicolumn{2}{|l|}{$\alpha_{2}$-Adrenergic agonist } \\
\hline Clonidine & $300 \mu \mathrm{g}$ \\
\hline \multicolumn{2}{|l|}{$\alpha$-Blocker } \\
\hline Doxazosin & $4 \mathrm{mg}$ \\
\hline \multicolumn{2}{|l|}{$\beta$-Blocker } \\
\hline Carvedilol & $25 \mathrm{mg}$ \\
\hline Bisoprolol & $5 \mathrm{mg}$ \\
\hline Metoprolol & $100 \mathrm{mg}$ \\
\hline Atenolol & $100 \mathrm{mg}$ \\
\hline \multicolumn{2}{|l|}{ Calcium channel blockers } \\
\hline Nifedipine & $60 \mathrm{mg}$ \\
\hline Felodipine (extended release) & $10 \mathrm{mg}$ \\
\hline Lacipidine & $6 \mathrm{mg}$ \\
\hline Nicardipine & $40 \mathrm{mg}$ \\
\hline Amlodipine & $10 \mathrm{mg}$ \\
\hline Manidipine & $20 \mathrm{mg}$ \\
\hline Lercanidipine & $20 \mathrm{mg}$ \\
\hline Verapamil & $160 \mathrm{mg}$ \\
\hline Diltiazem & $240 \mathrm{mg}$ \\
\hline \multicolumn{2}{|l|}{ Converting enzyme inhibitors } \\
\hline Enalapril & $20 \mathrm{mg}$ \\
\hline Ramipril & $10 \mathrm{mg}$ \\
\hline Lisinopril & $20 \mathrm{mg}$ \\
\hline Fosinopril & $20 \mathrm{mg}$ \\
\hline Perindopril & $4 \mathrm{mg}$ \\
\hline Zofenopril & $30 \mathrm{mg}$ \\
\hline Delapril & $30 \mathrm{mg}$ \\
\hline \multicolumn{2}{|l|}{ Angiotensin receptor blockers } \\
\hline Irbesartan & $300 \mathrm{mg}$ \\
\hline Valsartan & $160 \mathrm{mg}$ \\
\hline Candesartan & $16 \mathrm{mg}$ \\
\hline Losartan & $100 \mathrm{mg}$ \\
\hline Telmisartan & $80 \mathrm{mg}$ \\
\hline Eprosartan & $600 \mathrm{mg}$ \\
\hline Olmesartan & $20 \mathrm{mg}$ \\
\hline
\end{tabular}

\section{Disclosure Statement}

There are no conflicts of interest. 


\section{References}

$\checkmark 1$ The National High Blood Pressure Education Program Coordinating Committee: Seventh report of the Joint National Committee on Prevention, Detection, Evaluation, and Treatment of High Blood Pressure. Hypertension 2003;42:1206-1252.

$\checkmark 2$ Calhoun DA, Jones D, Textor S, Goff DC, Murphy TP, Toto RD, et al: American Heart Association Professional Education Committee: Resistant hypertension: diagnosis, evaluation, and treatment: a scientific statement from the American Heart Association Professional Education Committee of the Council for High Blood Pressure Research. Circulation 2008;117:510-526.

-3 Sarafidis PA, Bakris GL: Resistant hypertension. An overview of evaluation and treatment. J Am Coll Cardiol 2008;52:1749-1757.

-4 El Nahas AM, Bello AK: Chronic kidney disease. The global challenge. Lancet 2005;365: 331-340.

$\checkmark 5$ De Nicola L, Minutolo R, Bellizzi V, Zoccali C, Cianciaruso B, Andreucci VE, et al, for the TABLE in CKD Study Group: Achievement of target blood pressure levels in chronic kidney disease. A salty question? Am J Kidney Dis 2004;43:782-795.

-6 Bakris GL, Williams M, Dworkin L, Elliott WJ, Epstein M, Toto R, et al: Preserving renal function in adults with hypertension and diabetes: a consensus approach: National Kidney Foundation Hypertension and Diabetes Executive Committees Working Group. Am J Kidney Dis 2000;36:646-661.

7 Bakris GL, Weir MR, Shanifar S, Zhang Z, Douglas J, van Dijk DJ, et al: Effects of blood pressure level on progression of diabetic nephropathy. Results from the RENAAL Study. Arch Intern Med 2003;163:1555-1565.

- 8 Jafar TH, Stark PC, Schmid CH, Landa M, Maschio G, de Jong PE, et al, for the AIPRD Study Group: Progression of chronic kidney disease. The role of blood pressure control, proteinuria, and angiotensin-converting enzyme inhibition. Ann Intern Med 2003;139: 244-253.

\9 Sarnak MJ, Greene T, Wang X, Beck G, Kusek JW, Collins AJ, et al: The effect of a lower target blood pressure on the progression of kidney disease: long-term follow-up of the Modification of Diet in Renal Disease Study. Ann Intern Med 2005;142:342-351.

10 O'Seaghdha CM, Perkovic V, Lam TH, McGinn S, Barzi F, Gu DF, et al: Asia Pacific Cohort Studies Collaboration. Blood pressure is a major risk factor for renal death: an analysis of 560,352 participants from the Asia-Pacific region. Hypertension 2009;54:509-515.

11 Pahor M, Shorr RI, Somes GW, Cushman WC, Ferrucci L, Bailey JE, et al: Diureticbased treatment and cardiovascular events in patients with mild renal dysfunction enrolled in the Systolic Hypertension in the Elderly Program. Arch Intern Med 1998;158: 1340-1345.
12 Lucas MF, Quereda C, Teruel JL, Orte L, Marcen R, Ortuno J: Effect of hypertension before beginning dialysis on survival of hemodialysis patients. Am J Kidney Dis 2003; 41:814-821.

13 Sarnak MJ, Levey AS, Schoolwerth AC, Coresh J, Culleton B, Hamm LL, et al: American Heart Association Councils on Kidney in Cardiovascular Disease, High Blood Pressure Research, Clinical Cardiology, and Epidemiology and Prevention. Kidney disease as a risk factor for development of cardiovascular disease: a statement from the American Heart Association Councils on kidney in cardiovascular disease, high blood pressure research, clinical cardiology, and epidemiology and prevention. Hypertension 2003;42: 1050-1065.

14 De Nicola L, Minutolo R, Chiodini P, Zamboli P, Zoccali C, Castellino P, et al, for the TArget Blood Pressure LEvels in Chronic Kidney Disease (TABLE in CKD) Study Group: Global approach to cardiovascular risk in chronic kidney disease: reality and opportunities for intervention. Kidney Int 2006;69:538-545.

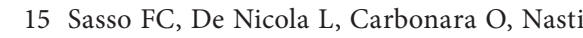
R, Minutolo R, Salvatore T, et al, for the NID2 (Nephropathy In Diabetes-Type 2) Study Group: Cardiovascular risk factors and disease management in type 2 diabetic patients with diabetic nephropathy. Diabetes Care 2006;29:498-503.

16 Minutolo R, De Nicola L, Zamboli P, Chiodini P, Signoriello G, Toderico C, et al: Management of hypertension in patients with CKD. Differences between primary and tertiary care settings. Am J Kidney Dis 2005;46: $18-25$.

17 Minutolo R, Sasso FC, Chiodini P, Cianciaruso B, Carbonara O, Zamboli P, et al: Management of cardiovascular risk factors in advanced type 2 diabetic nephropathy. A comparative analysis in nephrology, diabetology and primary care settings. J Hypertens 2006; 24:1655-1661.

18 Peralta CA, Hicks LS, Chertow GM, Ayanian JZ, Vittinghoff E, Lin F, Shlipak MG: Control of hypertension in adults with chronic kidney disease in the United States. Hypertension 2005;45:1119-1124.

19 Marìn R, Fernandez-Vega F, Gorostidi M, Ruilope LM, Díez J, Praga M, et al: COPARENAL (COntrol de la hiPertensión Arterial en Pacientes con Insuficiencia RENAL) study investigators: Blood pressure control in patients with chronic renal insufficiency in Spain: a cross-sectional study. J Hypertens 2006;24:395-402.

20 Schwenger V, Ritz E: Audit of antihypertensive treatment in patients with renal failure. Nephrol Dial Transplant 1998;13:30913095.
21 Dasgupta RJ, Madeley RJ, Pringle MAL, Savill J, Burden RP: Management of hypertension in patients developing end-stage renal failure. Q J Med 1999;92:519-525.

-22 Lazarus JM, Bourgoignie JJ, Buckalew VM, Greene T, Levey AS, Milas NC, et al: Achievement and safety of a low blood pressure goal in chronic renal disease. Hypertension 1997; 29:641-650.

23 Wright JT, Agodoa L, Contreras G, Greene T, Douglas JG, Lash J, et al: Successful blood pressure control in the African American Study of Kidney Disease and Hypertension. Arch Intern Med 2002;162:1636-1643.

-24 Berl T, Hunsicker LG, Lewis JB, Pfeffer MA, Porush JG, Rouleau JL, et al: Impact of achieved blood pressure on cardiovascular outcomes in the Irbesartan Diabetic Nephropathy Trial. J Am Soc Nephrol 2005; 16: 2170-2179.

25 National Kidney Foundation: K/DOQI clinical practice guidelines for chronic kidney disease: evaluation, classification and stratification. Am J Kidney Dis 2002;39:S1-S266.

$-26 \mathrm{~K} / \mathrm{DOQI}$ clinical practice guidelines on hypertension and antihypertensive agents in chronic kidney disease. Am J Kidney Dis 2004;43:S1-S230.

27 Dwyer J, Kenler SR: Assessment of nutritional status in renal disease; in Mitch WE, Klahr $S$ (eds): Nutrition and the Kidney, ed 2. Boston, Little, Brown, 1993, pp 61-95.

28 Agarwal R, Andersen MJ: Correlates of systolic hypertension in patients with chronic kidney disease. Hypertension 2005;46:514520.

29 Agarwal R, Light RP: GFR, proteinuria and circadian blood pressure. Nephrol Dial Transplant 2009;24:2400-2406.

30 Clausen P, Jensen JS, Jensen G, Borch-Johnsen K, Feldt-Rasmussen B: Elevated urinary albumin excretion is associated with impaired arterial dilatory capacity in clinically healthy subjects. Circulation 2001;103:18691874 .

- 31 Hermans MMH, Henry R, Dekker JM, Kooman JP, Kostense PJ, Nijpels G, et al: Estimated glomerular filtration rate and urinary albumin excretion are independently associated with greater arterial stiffness: the Hoorn Study. J Am Soc Nephrol 2007;18: 1942-1952.

32 De Zeeuw D, Remuzzi G, Parving HH, Keane WF, Zhang Z, Shahinfar S, et al: Albuminuria, a therapeutic target for cardiovascular protection in type 2 diabetic patients with nephropathy. Circulation 2004;110: 921-927.

-33 Hemmelgarn BR, Manns BJ, Lloyd A, James MT, Klarenbach S, Quinn RR, et al: Relation between kidney function, proteinuria, and adverse outcomes. JAMA 2010;303:423429. 
-34 Gaddam KK, Nishizaka MK, Pratt-Ubunama MN, Pimenta E, Aban I, Oparil S, Calhoun DA: Characterization of resistant hypertension: association between resistant hypertension, aldosterone, and persistent intravascular volume expansion. Arch Intern Med 2008;168:1159-1164.

- 35 Pimenta E, Gaddam KK, Oparil S, Aban I, Husain S, Dell'Italia LJ, Calhoun DA: Effects of dietary sodium reduction on blood pressure in subjects with resistant hypertension. Results from a randomized trial. Hypertension 2009;54:475-481.
36 Campese VM, Mitra N, Sandee D: Hypertension in renal parenchymal disease. Why is it so resistant to treatment? Kidney Int 2006; 69:967-973.

-37 Burns KD: Angiotensin II and its receptors in the diabetic kidney. Am J Kidney Dis 2000;36:449-467.

38 Velez JCQ: The importance of the intrarenal renin-angiotensin system. Nat Clin Pract Nephrol 2009;5:89-100.

39 Salles GF, Cardoso CR, Muxfeldt ES: Prognostic influence of office and ambulatory blood pressures in resistant hypertension. Arch Intern Med 2008;168:2340-2346.

-40 Muxfeldt ES, Cardoso CR, Salles GF: Prognostic value of nocturnal blood pressure reduction in resistant hypertension. Arch Intern Med 2009;169:874-80.
41 Brown MJ: Aliskiren. Circulation 2008;118: 773-784.

42 Weber MA, Black H, Bakris G, Krum H, Linas S, Weiss R, et al: A selective endothelinreceptor antagonist to reduce blood pressure in patients with treatment-resistant hypertension: a randomised, double-blind, placebo-controlled trial. Lancet 2009;374:14231431.

43 Krum H, Schlaich M, Whitbourn R, Sobotka PA, Sadowski J, Bartus K, et al: Catheterbased renal sympathetic denervation for resistant hypertension: a multicentre safety and proof-of-principle cohort study. Lancet 2009;373:1275-1281. 